\title{
New Online Communities and New Identity Making: The Curious Case of the Kurdish Diaspora
}

\author{
Jowan Mahmod ${ }^{1}$ \\ Middle East Research Institute, Sweden
}

\begin{abstract}
The central argument in this paper is that an intimately linked set of processes - diaspora, transnationalism and communication technologies-are creating new maps of identity, which diverge from traditional forms of identity construction within the physical and national territory. By exploring this triangular relationship between diasporas, transnationalism and digital communication, this paper highlights a range of new identity experiences that can serve as a timely example in a wider context of how traditional spheres of identity such as ethnicity, culture, gender, and religion, which have hitherto provided people with firm identities, are being contested in an age of digital technologies and new global collaborations. Based on a comparative interdisciplinary research study, including multi-sited (online-offline) methodologies, the empirical examples examined here show how diasporic Kurds have developed a new form of transnational and global consciousness through their online activities-a consciousness that transcends the national and diasporic dual consciousness. Kurdish diasporas have begun to display a growing awareness of identity differences not only between diaspora and homeland Kurds, but also between Kurdish diasporas settled in various Western countries. Therefore, rather than speaking of the inflationary "imagined diaspora," this paper highlights the fluidity of diasporic identities and shows how a victim diaspora can morph into a transnational and global diaspora. The acknowledgement of identity differences and the de-mythologization of the homeland complicates the concept of the imagined community, which has hitherto not been sufficiently recognized in academic scholarship.
\end{abstract}

Keywords: diaspora, identity, transnationalism, Kurds, internet.

\section{Introduction}

The level of cross-border activity among diasporas has become something of a litmus test for integration in Europe, and it has often been considered, both within and beyond academia, that transnational and online practices among diasporas strengthen their collective identity (Georgiou, 2012). While this is one way of understanding online practices, transnationalism should not be merely interpreted as a process of strengthening cultural identities. Instead, as my own research has shown, and on which this paper is based ${ }^{2}$, transnational practices and media participation may constitute a process of de-mythologization of the imagined homeland. As individuals become exposed to more diversity and social plurality, new discourses relating to internal differences and the flaws inherent in the (imagined) notions of a coherent and homogenous identity are emerging.

The global platforms and intense exchanges that transnationalism entails may indeed encourage interethnic and counter-national sentiments that problematize the concept of the "imagined community," which is often used in the context of diasporas to explain how the homeland is retained in narratives and fragments of memory. Diaspora and media studies have recurrently portrayed diasporic people as part of an "imagined diaspora" (Karim, 2007). The original concept of the imagined community, coined by Benedict Anderson (2006), refers to the idea that nobody within a nation will ever know more than a handful of people yet share a strong attachment and sense of unity to a much larger national collective group. Owing to the printing press, invented by Gutenberg in the fifteenth century, as well as the circulation of books and information, this "print capitalism" enabled the nationstate to present itself as an imagined and homogenous culture, according to Anderson. Most nations or collective political movements can be considered as being imagined.

The concept of imagined community or diaspora may be more explicable in the Kurdish context as they not only lack a nation-state but are also politically divided between the four states of Iraq, Syria, Turkey, and Iran, states which have all refused to recognize Kurdish national and ethnic identity and its political and cultural expressions (McDowall, 2004; Ugurlu, 2014). Despite this, the terminology of young diasporic Kurds often describes their fragmented country as a single national entity. Based on similar identity expressions and intensified

\footnotetext{
${ }^{1}$ Correspondence: E-mail jowan.m@gmail.com

${ }^{2}$ This paper draws from the ethnographic research conducted as part of my Ph.D. research at Goldsmiths University of London, completed in 2012.
} 
online practices, earlier studies (e.g. Eriksen, 2006) have concluded that Kurdish identity has been reinforced by second and third generation Kurds growing up in Europe.

But if diasporic populations are subject to transnationalism and multiple cultures, how does this interfere with the imaginings of a diaspora whose people are stateless? If the national community is an imagined construction, as Anderson says, how can diasporas possibly interrupt this imagining? By studying transnational Kurdish online communities and interactions - a subject comparatively underexplored in academic scholarship this paper critically re-examines such analyses, challenging the orthodoxies that characterize prevailing depictions of the diaspora-homeland nexus. The main argument here is that an intimately linked set of processes that takes in diaspora, transnationalism, and new communication technologies may provide a powerful vehicle for producing new insights into the diasporic consciousness. This paper examines diasporas as an intellectualization of human mobility and dispersion, and addresses the ways in which ostensibly strong identities struggle in the face of increased diversity and social plurality which exceed the confines set in place by the nation-state and the gatekeepers of old media formats.

Drawing from an online ethnographic study of a Kurdish transnational community and in-depth interviews with its members located in Europe ${ }^{3}$, the paper sheds light on how present-day online practices allow for different articulations of identity. The history of the Kurdish diaspora, the new communication technologies, and quotidian transnational activities bring out a series of processes of new identity formation. This can serve as an example in a broader context of how traditional spheres of identity (i.e. ethnicity, culture, gender, and religion) within the physical territory, which have hitherto provided people with firm identities, are now being contested in an age of digital technologies and new transnational collaborations and global links.

National and cultural identity has increasingly become a burning political issue beyond the diaspora context. From the US to Europe, the state has come under external and internal pressure as citizens become increasingly disenchanted. The rise of nationalism, religious extremism, polarization, and the Brexit vote, shows a Europe that is struggling with conflicting visions of identity. These events, together with the epidemic of building walls, are strong reactions to what may be, as predicted by cultural theorists and sociologists such as Stuart Hall (1997) and Ulf Hannerz (1996), the erosion of national formations. The constructions of new walls represent a swan-song for the conventional notion of the nexus between identity and territory, in an increasingly linked, hybridized and fluid modern world (Brown, cited in Ponzanesi \& Leurs, 2014). New forms of cooperation are emerging, shaped by common ideas, values, and interests. The ways in which online discussions expose the different thoughts of Americans, British, Christians, Muslims, women - or in this case Kurds - points to altered learning processes and a new consciousness as a different field of visual representation opens up encompassing a profound change in norms, values, and behaviours, as this paper will illustrate.

A diaspora perspective is promising because it identifies the ways in which identities have and continue to be transformed through relocation and cross-cultural interaction (Hall, 1997), and which are becoming further deterritorialized by digital technologies. Diasporic identities are the most dynamic and unstable identities and also the least understood, and are thus in need of more attention and innovative methodological and theoretical approaches. ${ }^{4}$

\section{The Interplay Between the Self and the Other in the Online World}

Like many other scholars, I have been confronted with the complexity and the contradictory nature of identities in general, and among the Kurdish diasporas in particular. "Kurdish" is a complex term with numerous connotations. Linguistic, religious, national, social, cultural diversity and territorial divisions among Kurds have made studying them more complicated, but in an age of globalization, weakened nation-states, immigration, polarization, and fragmented identities, I believe that Kurds can say much about these issues - not despite their complexity but because of it.

Online networks, with their ever-expanding array of relationships and open communications, increasingly contest the national territory as the main source of community, culture and identity. The social networks have thus become significant enablers of new voices and new realities, especially for women and minorities, breeding increased scepticism towards inherited belief systems and established norms within cultures, and posing new challenges to the way people have imagined their own groups and others (Solas \& Sutton, 2018; Tarman \& Dev, 2018).

While the concept of the imagined community has helped explain how and why people feel a sense of commonality and belonging, it has also illuminated why people distinguish themselves from others outside their community. One of the determining factors in the creation of cultural identity and community is difference (Appadurai, 2006). The idea of a statehood has rooted in the human mind a map of imagined communities in which

\footnotetext{
${ }^{3}$ Specific focus has been given to the Kurdish diasporas in UK and Sweden, and with Kurds in the homeland as a point of reference in the analysis.

${ }^{4}$ The internet can provide an exclusive space for research on identity as it offers anonymity and confidentiality, allowing participants to authentically discuss sensitive or taboo topics that otherwise might not make it to offline interviews due to aspects of shame and discomfort. Therefore, the mixed-methods of online-offline research, which is still an uncommon approach in academia, has been both challenging and significantly rewarding to gain new insights and material.
} 
internal differences are minimized and external differences are maximized (Tajfel, 1981). The imagined community absorbs all he internal differences of class, region, and social capital, and the inevitable result is a feeling of "us" and "them." Such dichotomies are reproduced and reinforced within nations through the overemphasis of boundaries between majorities and minorities to separate the dominant national group from other groups and underscore that dominance (Appadurai, 2006; Ilyas, 2018; Strunc, 2019; Thangaraj, 2015; Woofter, 2019). Identity is thus constructed from the production of a set of opposites (Hall, 1997; Jones, 2019). One of the founding studies of such opposites in terms of the Self and Other is Edward Said's Orientalism (1978). Said's main discourse demonstrated how "the Orient helped to define Europe (or the West) as its contrasting image, idea, personality, experience.” (p. 1-2).

From a different perspective, I discuss the mechanism of internal othering that has emerged from the empirical research (see also Mahmod, 2016). Within this framework of internal othering, it is crucial to consider how minorities use agency in the process of differentiating themselves, even within their own groups. The shift from the west-east dichotomy to internal othering confronts the homogenization of people on either side of the hyphen. The important underlying point is that the discourse of Orientalism has overwhelmingly portrayed the East as passive and homogenous. Earlier modifications of Said's original formulation have been made by Pyke and Dang (2003) and Nancy Abelmann (2009) on "intraethnic othering" to describe the deliberate separation within collective groups that echoes the cosmopolitan-backward dichotomy of Orientalism. I believe that internal othering is best captured through an ethnographic approach, by studying the online environment to track complex transnational connections and the new dynamics they generate.

It is still uncertain how we should understand these new platforms that continue to evolve so rapidly, but the borderless online territory, which is stimulated by performative participation rather than by claims of national, ethnic, or religious membership (Mishra, 2006), is now disrupting established associations and affiliations of identity and belonging. This depiction of the global public sphere lends itself well to understanding how ideas, dialogues, and relationships surpass identity conventions in this open and deeply linked community. Without dismissing the presence of identity politics in the online world, it is the individual conduct - thought and action that has a cumulative effect on the Self as the mechanics of power and regulation change online and affect our behaviours and expectations. Put differently, the boundaries between the Self and the Other become less clear in the online environment when "they" are not present (or at least not represented) and "we" breaks up into many subgroups. It is this constant interplay between the Self and the Other in the online sphere that shows a tendency towards the rejection of ethnicity as the locus of belonging (Mahmod, 2016).

\section{Unpacking Kurdish Identity}

In the following sections I will present how new maps of identity experience differ from traditional forms of identity-making that have commonly been shaped by the nation-state, institutions, education, and national symbols such as the flag and the national anthem (Tajfel, 1981). Most young Kurds become members of online communities in order to share a common notion of identity and to unite in important cultural and political issues. Digital technologies in many ways represent a new form of power for individuals and "small players," who until recently had little chance of having voice, much less gaining a hearing and making a difference. This is particularly important in the context of oppressed groups and victim diasporas, to which Kurds belong. However, these new ways of participation and interaction have resulted in an unforeseen explosion of public discourse, while the separation between public and private spheres becomes increasingly blurred.

The empirical material ${ }^{5}$ shows different discourses from the efforts to maintain a strict sense of Kurdish identity, often composed of tragedies and painful stories, to the deviation from essentialist notions of identity that aim to redefine traditional notions of culture and belonging. The former has been extensively explored by Kurdish studies scholars emphasizing homeland struggles and victimhood. But the new online environment has allowed Kurds to ponder new issues that have rooted themselves and blossomed during their upbringings in Sweden, the UK and beyond (Mahmod, 2016). These exchanges reveal a new discourse that more explicitly shows different ways of understanding Kurdish identity in its different settings and phases of migration more explicitly. This in turn produces new narratives that demand a reconsideration of the traditional ways in which we understand diaspora processes and identity-making. The following extracts offer insights into the new discourses produced by young Kurdish women and men as they interact online and become authors and readers of thousands of online posts over the years, sharing thoughts and emotions for which online participant observation has been an especially valuable methodological approach that captures dimensions and insights that would otherwise go unnoticed (Mahmod, 2018).

\footnotetext{
${ }^{5}$ The empirical material consists largely of online conversations from the transnational community Viva Kurdistan (VK). VK was the only transnational Kurdish community of its kind, composed of eight different forums: Sweden, the UK, Denmark, Norway, Germany, Holland, France, and Kurdistan (north Iraq). During the online ethnography (2010-2011), I collected thousands of posts from the main forums-Swedish, British, and Kurdish forums-and from which I analysed key themes related to the research questions. This was followed by qualitative interviews with members of the site, located in Sweden, the UK, and in the Kurdish region of Iraq.
} 


\title{
Online Anonymity as a Weapon Against Gender Inequality
}

Conversations in the Kurdish online community cover a range of topics, from gender and sexuality to culture, religion and political ideologies. The length and nature of the discussion threads show the seriousness of these issues. One of the most popular discussed topics discussed was gender norms, sexuality and marital obligations, and one determining factor for this was the ability to stay anonymous.

\begin{abstract}
"I am a Kurdish girl and a proud one. But I have biological needs, just like anyone else. I have sexual needs. Just like men, I also have, as a Kurdish girl, been passed on by Western individualism. I'm open about this here, but when I marry my future Kurdish husband, I won't tell him about my experiences."

- Western Individualism and Sexuality, Swedish Forum
\end{abstract}

Young Kurds turn to the online forums to test and contest certain ideas and norms that are often surrounded by perceptions of discomfort and embarrassment but are now more easily discussed in the comparatively anonymous online sphere. Such otherwise limitations can be seen from the post above, revealing that the participant has to hide her life experiences (see also Mahmod, 2016). Diasporic Kurds often speak from a liberal Western perspective online, ignoring familial and cultural expectations. Online, they are freer to talk about their lives as individuals in diasporic settings, not to expose their private affairs but to seek recognition within the community. Young women above all are more willing to offer personal experiences into the online public spheres, thus changing attitudes to privacy and taboo without any potentially serious consequences. This way of broadcasting their daily lives, experiences and concerns inevitably leads to an offline cultural shift (see interview extracts below) as the boundary between public and private becomes more blurred, potentially leading to significant social change.

Gender attitudes and transgressive gender behaviors are often used used as tools to categorize insiders and outsiders (Schein, 2000; Thangaraj, 2015). Women are viewed as the "bearer of collectivities" (Yuval-Davis, 1993) and earlier interviews with diasporic Kurdish women confirm how gender issues are usually side-lined in favor of nation-building projects (Baser, 2011). But online debates provide new dimensions for internal contestations, showing how women confront their depiction as "cultural symbols" whose virtue is supposedly assumed by upholding traditions (Gopinath, 2005).

\section{Online Insults as Identity Markers}

Participants in the online community adopt multiple identifications and standpoints of commonality and differences. Many posts allude to essentialist notions of Kurdish identity as a fait accompli; emotions, pride, and memories capture the essence of Kurdishness. But these convictions are starting to collide with altered and competing understandings of what it means to be a Kurd in diaspora. The following extracts illustrate different layers of internal othering.

\author{
"You're not a real Kurd, at all. A Turk in disguise who is trying to ruin this \\ community for sure" \\ -Iraqi Election, Swedish Forum
}

\begin{abstract}
"Why do you call yourself a Kurd? There is nothing Kurdish in you the way you speak about our identity and mission. You've become completely un-Kurdish." -Historical perspective: Abdullah Öcalan and Massoud Barzani cooperation! Swedish Forum
\end{abstract}

Terms like "un-Kurdish" are a offensive and are used by participants to imply assimilation or a weakening of Kurdish identity (Mahmod, 2016). Such insults typically arise in topics relating to political affairs. But when Kurds identify co-ethnics by these names, they implicitly diverge from the essentialist views of ethnic affiliation that they otherwise hold. Such terminology essentialize the Kurdish identity, turning the threads into several pages of discussion including insults and "flames." This kind of essentialization can be common among minorities. In fact, James Clifford (1994) explains, some of the most violent articulations can be found among diaspora populations, but those discourses can be understood as "weapons of the (relatively) weak" (p. 307), which allows collective representation and the opportunity to pose challenges to hegemonies. However, while the intention here is to maintain a sense of wholesome Kurdish identity, it permits the use of exclusionary terminology in terms of who is to be considered a Kurd and who is not.

In the post-Saddam era, Kurdish political agendas have been dominated by the rebuilding of infrastructure and the recreation of a Kurdistan Regional Government, and dynamics have subsequently changed considerably. 
Internal differences were present earlier, but the region's internal narratives have been seriously affected by previous exogenous struggles characterized by a kind of trauma never fully understood nor fully dealt with (Hirsch, 1997). Eid and Karim (2014) explain that identities within the cognitive frames of Self and Other are moulded by particular discourses at specific times. While ethnic groups form a larger Self in the context of foreign affairs, that same Self splinters into various degrees of otherness in the context of domestic policies. This is not unique to Kurds, although their diversity has been overshadowed by a greater and more externalized sense of "us" and "them."

With the post-Saddam decline of nationalism, and with more power within their own territory, diversity among Kurds has surfaced and intensified. The collective Kurdish social identity has not disappeared, but no longer influences the social, political or ontological conceptualization under which they overwhelmingly lived prior to the removal of Saddam Hussein. Kurds have now become more attuned to their inner fragmentations as part of a reordering which impacts on national consciousness and questions the social collective identity, not in terms of its disappearance but in the light of its changing form (Hall, 1997).

\section{Rejecting Ethnicity as a Locus of Commonality}

The growing awareness of and scepticism towards the homogenous notion of community and identity among Kurds - even as they continue to strive for a distinctive collective identity and find themselves politically closer to a Kurdish statehood - speaks to the discourse on the weakening of nations as a source of identity (Hall, 1997). Growing up as part of two or more cultures, speaking multiple languages and living through transnational practices have influenced identities and cultures, but the sudden and unexpected increase in cultural, social, and political pluralism caused by the rapid evolution of digital media technologies has further made the Kurdish identity more fluid. The historical pattern of tragedy that served as an important site for political mobilization among diasporic Kurds has been overtaken by different ideologies competing for attention and support.

Through their exchanges in the online community, homeland Kurds have often expressed concerns for diasporic Kurds who they think have become more European and less attached to their own local culture and traditions. The ubiquitous social connections between diaspora members and their peers in the homeland are thus not sufficient for maintaining the formation of Kurdish identity. An informative way of understanding the fluidity of identities in the diasporic community comes from the perspective of local people in the homeland who are more sensitive to discerning changes at a distance that cumulatively result in large-scale transformations.

If authenticity is based on traditional Kurdish cultural factors, reactions arise when those are no longer seen to represent diasporic Kurds. Sunaina Maira (2002) explains in her ethnographic work on South Asian Americans that this dissonance arises because the notion of authentic identity itself becomes confused, and secondgeneration migrants attempt to construct their own notions of authenticity. This is exemplified by the following views from the Kurdish community:

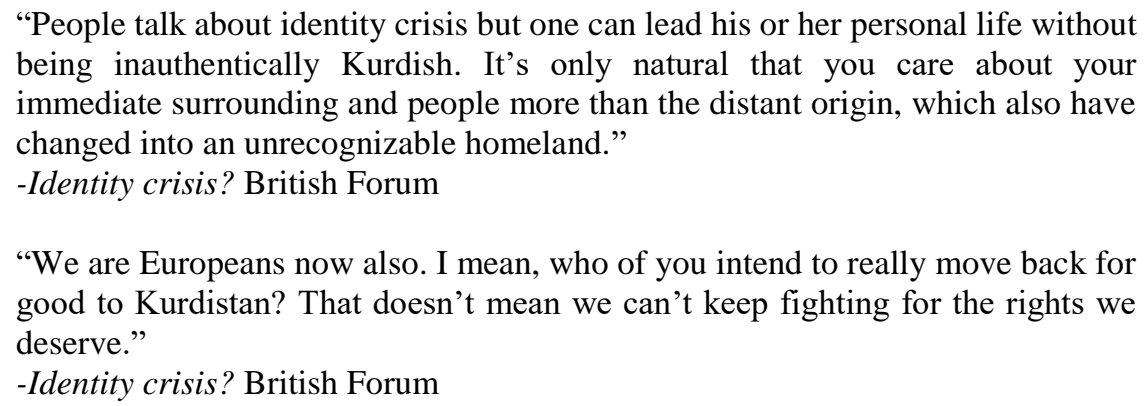

"We are Europeans now also. I mean, who of you intend to really move back for good to Kurdistan? That doesn't mean we can't keep fighting for the rights we deserve."

-Identity crisis? British Forum

The second extract compels us to distinguish transnational political engagements, which aim to improve the political situation in the homeland, from personal lifestyles that now include new habits, practices, friends and concerns that stem from an altered sense of community and belonging. The ideas and practices of cosmopolitanism diaspora citizens articulate is in conflict with the nationalist ideology, and in this regard, diasporic cultural forms can never be absolutely nationalist (Clifford, 1994). One could say that the identity crisis appears when young Kurds seek to escape their cultural limitations yet are unable to abandon the culture and liberation movement that their parents and grand-parents took such a heavy toll for. I see this crisis expressing itself among young Kurds when they strive to maintain a connection with the Kurdish community, as they at the same time adjust and reproduce themselves and confront those who expect cultures to remain "neat little parcels" (Wise, 2000, p. 306). This is perhaps best illustrated through the labels of "freshies."

"It is fairly easy to identify the imports with their outdated outfits, broken Swedish and overall a backward mindset that doesn't fit in.." 


\section{-Define the word import? Swedish Forum}

The term "freshie," or "import" in Swedish, is applied as a derogatory social marker by the diaspora members to distinguish the social distance between themselves and other more recently arrived Kurds when gauging how integrated or assimilated they are (Mahmod, 2016; Pyke \& Dang, 2003; Thangaraj, 2014, 2015). But conversely, internal othering is also used to condemn the integrated Kurds for being "too European" and using a snobby language, and accusing them of being inappropriately dressed. Such rebukes evoked strong responses.

"An integrated Kurd, educated and well-articulative is not a traitor. Nor has he or she necessarily turned back on the Kurds, but rather is an example that freshies should follow. Kurdistan and Sweden need more of these Kurds than the antiliberal and backward mentality if anything."

-Define the term import, Swedish Forum

This kind of intra-ethnic othering employed by the forum members to monitor and control social and cultural behaviour has also been a common feature of Asian Americans dialogue (Pyke \& Dang, 2003). Such insults have been paid little attention in research on diasporic youth, but represent a common aspect of the reproduction of themselves in new settings.

Terminologies of identity and ethnicity deployed by younger generations expose diverse ethnic and cultural ideologies, informing us about different identity routes. Unlike other researchers who may simply interpret this as internalized racism (see e.g. Pyke \& Dang, 2003), I believe it is important not to just interpret such comments as insults but to use them as a measure of how different phases of migration, integration processes and the social and cultural identity of the settlement country have impacted diasporas. Differentiations among Kurds are not restricted to old diasporas versus new migrants but also appear between diasporas growing up in different European countries, and can tell us a great deal about the ways in which diasporic patterns and formations are influenced by the identity politics of the state in which they reside.

Displacement is an important and influential element in understanding the processes diasporas undergo (Brah, 2005), and should not merely be considered between different ethnic diasporas but also within groups. We can then consider class, gender, sexuality, social capital, habitus and other socio-economic factors that may often be overlooked within diaspora studies. Class, for example, is a particularly important category that can disrupt group homogeneity (Thangaraj, 2014). The following section looks closer at this phenomenon.

\section{From Notions of Victimhood to a Sense of Entitlement}

For the children of first-generation migrants to Europe, the notion of how to be a Kurd does not always accord with nationalistic projects, victimization sentiments or nostalgia. Young Kurds dispute supranational patterns by opposing established traditions. They promote a sense of Kurdishness that increasingly takes its cue from the internationally mediated realms of art, culture, music, fashion, sport and literature. One British Kurd explained that "if it is... oh you can't get a tattoo, or piercing, then I don't really want to be a part of that culture." Such observations offer precious insights that illustrate how attitudes have moved from victimhood to a sense of ownership and entitlement. Rather than viewing diasporas merely as people connected by shared histories and living in in-between spaces, recognizing diasporas as social forms (Vertovec, 2000) can allow us to understand how identities continue to transform through relocation and cross-cultural and national interaction.

"I am as much part of the Swedish society as any other Swede. I contribute more than the average Svensson to the society. Hell I'm more Swedish than Kurdish most of the time, whatever that means."

-Soon they will throw us out, Sweden Forum

Statements like these encourage Kurds to identify themselves as citizens and not as guests, with a right not only to be recognized as such but also to negotiate the terms of that recognition (Modood, 2010). It is apparent, and will become more evident in the next section, that diasporic individuals have radically transformed many of their social and cultural practices, dissolving meta-narratives of diasporic home longing. In the process of unpacking old Kurdish identities and expressing new ones, whatever challenges it may lead to, Kurds have demonstrated that a sense of belonging to one's origin country and adaption to the new country are not mutually exclusive but do entail changed identities. 


\title{
Online-Offline Nuances and Contradictions
}

To understand how diasporic Kurds are influenced by online activities and learn how the same topics are discussed face-to-face, I conducted interviews with online forum members in Sweden and the UK as well as with those residing in the homeland (Kurdistan, Iraq). The discrepancies between the unconventional forms of expressing confidential concerns online and offline became more evident during the interviews, which has epistemological implications in terms of how knowledge is produced and what reality-status a researcher gives the material. The concept of viewing identity as a process of negotiation between the inside and outside, the personal and the public, can be illustrated by the following online example.

\begin{abstract}
"Where are you from? If you hear that question in a normal situation, it is common that you answer that you are a Kurd. [...] What happens if you ask yourself that question? Is the same response given? Can you see yourself as only an individual without categories?"

- Where are you from? Swedish Forum
\end{abstract}

A normal situation refers here to the conventional single place of the offline community with its social boundaries and embedded scripts of how to conduct oneself in order to be defined as a member of the national or ethnic community. The implication in the quote is that the digital community dissolve such established scripts to argue that identity-making occurs across decentralized and open social structures. The internet does not mirror the subconscious offline environment (Maddox, 2016); it permits uncensored answers to questions that are raised.

The main aim for most members of the online community is to meet co-ethnics and discuss Kurdish matters. Before joining online forums, diasporic Kurds gained their understanding of Kurdish discourses from their parents, friends, and satellite Kurdish channels, which effectively united Kurds in accordance with the observations made by Anderson (2006), who identified the strength of traditional media in reinforcing national identity. My interview participants all explained in their different ways how much of their strong Kurdish sentiments were handed down by their parents and television, as well as how they conflicted with their online experiences.

"I was surprised to see how many sub-groups of Kurds there were online, which did not resonate with the view and experience I had before I joined the community.

-Male interviewee, 28, UK

The hyper-connectivity enabled by digital media may have brought Kurds closer to each other, but the disruptive technologies have at the same time created a distance between the new realities and the old nostalgic narratives. Such awakenings make the distinction between online and offline identities less meaningful than earlier studies concluded. These tendencies could also suggest that the pace of change that leads to more dynamic and changeable identities is increasing. Having said that, the participants also engaged more in Kurdish events than before thanks to the new feelings of transnational connectedness.

“...like attending demonstrations against the cruelty of authoritarian states, seminars and concerts, and also making new Kurdish friends."

-Male interviewee, 23, Sweden

Members of the online community continue their interactions offline, attending seminars and events as well as travelling to meet fellow Kurds in other countries. However, transnationalism is not just about directing activities outwards and maintaining ties - which has been the main focus of academic writing in diaspora and media studies - but is also about the lessons that diaspora members learn about multiple communities and attachments and the differences they generate. Features such as anonymity, privacy, two-way communications and a large readership spawn new forms of social and cultural interactions, inciting new experiences of identity. When stories of the past and of places left behind, often mythologized through nostalgia, reach actual physical and socio-cultural settings (Gajjala, 2002), the imagined community, once held sacred, is shaken to its core. These are not stories from "back home" (which is no longer the same place they left) nor from the new host state, but from a position that transcends the two (Mahmod, 2016). There is no longer a horizontal line between the homeland and diaspora, because lateral engagements now exist between Kurdish diasporas in different Western geographies. This redefinition exceeds the national consciousness outlined by Anderson and even the concept of double consciousness employed to portray diasporas' state of mind (Du Bois, 1903), as online and offline communities are now breaking from the duality of the homeland and the country of settlement. The argument here is that neither the national nor the dual diasporic consciousness is enough to describe and understand the emergence of new forms 
of identities that are increasingly shaped by transnational and global movements of people and information, whether actual or virtual.

The apparent differences in this context, which are often interpreted as disunities that hinder an independent Kurdistan, often cause disappointment among diasporic Kurds. Online interactions shape the way Kurds think and feel about key concerns, creating new realities that contest and redefine their own self-perceptions as Kurds as much as Swedes or Brits.

"[Viva Kurdistan] made me think it's larger than just being Kurdish, we are all human beings. I could get on with a person who is English much better than I would with a Kurd. But Kurdish nationalism dictates when in a fight, if the Kurds and the English are fighting, I should back up the Kurds. And I just thought, what sense does that make? So, why must this mean that we should automatically feel closer?"

-Male interviewee, $18, \mathrm{UK}$

Younger generations of Kurds with years of online experiences and interactions are compelled to think about what it means to be a Kurd and how to deal with changing discourses. As I listened to the young man quoted above, it became clear that he was rejecting ethnicity as a locus for people to "automatically feel closer" and belong to each other. Other signifiers are now more important for him, such as world-view, interests, practices and values that can make him feel more compatible with British people than with Kurds. His explanation convinced me that his altered consciousness of what it means to be a Kurd demonstrated that cultural commonality is not coterminous in online and offline environments. While such a frank objection to Kurdish homogeneity was previously overshadowed by the Kurdish victimhood discourse, it has in recent years become more common and visible online.

\section{Conclusions}

Perhaps the most vital question in diaspora studies is what we can gain from studying diasporas and how it can help us understanding identity, belonging, nationalism and human mobility? In the light of the empirical material presented in this paper, I argue that the application of Anderson's concept of the imagined community onto diasporas overwhelmingly disregards their evolving natures, in particular the socio-cultural flux present within younger generations. Diasporas are often linked with idealistic imaginings of a return, resulting in outmoded formulations of identity that might implicitly strengthen their otherness.

This paper shows the conflicting views and emotions among young diasporic Kurds, and their changed views that challenge the Kurdish perceptions of identity as a static and unified entity. One could ask why we should pay attention to the derogatory terminology used by individuals from the same ethnic group that imply increased polarization? Why shift focus from the uniting forces of the new communication technologies to the tensions they bring by uncovering differences that work against the national unity? The answer to this is two-fold. First, the language or politics of offense has become increasingly common in the online sphere. Some would say it has entered a whole new level of polarization in the Trump era. This is therefore in need of more attention and exploration. As I have argued elsewhere, online flames and insults should not simply be dismissed as intent rudeness, but need to be analysed within their contexts in which they are linked to important issues of identity and difference, and the blurring of the political relationship between "us" and "them.". This brings me to a second point. In the complex terrain between the West and East, shaped by Self and Other, by majorities and minorities, we should also recognize internal othering in a wider multicultural context that generally pitches the homogenous proclivities of ethnicities. The national territory has until now been the framework on which identity has been constructed, creating imagined communities despite the fact that our everyday lives tell different stories involving a more diverse and complex virtual outlook on unity with people across ethnicities. Online hyper-connectivity and cultural saturation have increasingly displaced the Self and the Other. If nationalism was one of the most influential political ideologies at the beginning of the twentieth century, mobility, transnationalism and change appear to be key features of the twenty-first century, even though they face conflict from forces that long for a return to the imagined past.

While change of the human mind is slow, abstract and hard to discern, diasporas, who are more mobile than people rooted in one nation, capture these changes in unique ways. By way of dismissing socially-produced scripts, Kurds in diaspora demonstrate a new, multiple and transnational consciousness channelled by both the physical places they are attached to and the values they share with members outside of the ethnic community; rather than the myths and memories on which their imagined community has been built. This is an important insight that demonstrates the weakening of essentialist ideas and the kind of identity politics Kurds once adopted and relied on in order to remain distinctively Kurdish. Online experiences among diasporic Kurds have taught them that difference and change lie at the root of their Kurdish identity - and indeed all other types of identities.

Diasporic consciousness can therefore represent an interpretation of the existential condition of mobility and the deterritorialization of identities in this global digital era. We should not approach victim diasporas as being 
characterized merely by painful histories, but rather as a lens through which we can understand dynamic and unstable identities that are increasingly becoming part of people's realities. In this way, diasporism can provide insight into a condition of post-identity which is not bound by fixed national, religious or cultural boundaries. Diasporas do not just contribute to the understanding of the lived experiences of migrants, but together with new technology and transnationalism also expose a map of social structures and diversities that have hitherto been concealed and continue to be forcibly controlled in some authoritarian states through the shut-down of social media channels to maintain the imagined homogenous community.

Finally, my case study demonstrates that adaption is not an effortless process. Diasporic populations often have tragic stories of violence and assimilationist strategies in the homeland, and in the Kurdish case even experiences of genocide. There are tensions between migrants and host society as they attempt to settle in, but there are also tensions within migrant groups as they negotiate a place that sits comfortably between the old and the new. The tensions within diasporic groups therefore constitutes an important source of academic research on new identity construction and policy-making for questions of integration and diversity and multiculturalism.

\section{Acknowledgements}

Special thanks to Dr. Stanley Thangaraj for his valuable comments and suggestions.

\section{References}

Abelmann, N. (2009). The intimate university: Korean American students and the problems of segregation. Durham, NC: Duke University Press.

Anderson, B. (2006). Imagined communities: Reflections on the origin and spread of nationalism. London, UK: Verso.

Appadurai, A. (2006). Fear of small numbers: An essay on the geography of anger. Durham, NC: Duke University Press Books.

Baser, B. (2011). Kurdish diaspora political activism in Europe with a particular focus on Great Britain. Diaspora Dialogues for Development and Peace Project. Berlin, Germany: Berghof Peace Support. Retrieved from https://www.kurdipedia.org/files/books/2013/88667.PDF?ver=130240729740938724

Brah, A. (2005). Cartographies of diaspora: Contesting identities. London, UK; New York, NY: Routledge.

Clifford, J. (1994). Further inflections: Toward ethnographies of the future cultural. Anthropology, 9(3), 302-338. Retrieved from https://www.jstor.org/stable/656365?seq=1\#page_scan_tab_contents

Du Bois, W. E. B. (1903). The souls of black folk. New York, NY: Dover Publications.

Eriksen, T. H. (2006). Nations in cyberspace. Short version of the 2006 Ernst Gellner lecture, delivered at the Asen conference. London School of Economics, 27 March. Retrieved from http://www.media-anthropology.net/eriksen_nationscyberspace.pdf

Gajjala, R. (2002). An interrupted postcolonial/feminist cyberethnography: complicity and resistance in the "cyberfield." Feminist Media Studies 2(2), 177-193. https://doi.org/10.1080/14680770220150854

Georgiou, M. (2012). Media, diaspora and the transnational context: Cosmopolitanizing cross-national comparative research? In I. Volkmer (Ed.), The handbook of global media research (pp. 365-380). Oxford, UK: Wiley-Blackwell

Gopinath, G. (2005). Impossible desires: Queer diasporas and South Asian public cultures. Durham, NC: Duke University Press.

Hall, S. (1997). The local and the global: Globalization and ethnicity. In A. D. King (Ed.), Culture, globalization and the world-system: Contemporary conditions for the representation of identity (pp. 19-40). Basingstoke, UK: Macmillan.

Hannerz, U. (1996). Transnational connections: Culture, people, places. London, UK: Taylor \& Francis.

Hirsch, M. (1997). Family frames: Photography, narrative and postmemory. Cambridge, MA: Harvard University Press.

Ilyas, M . (2018). Expatriate Experience and the Fictional World of Diaspora. Journal of Social Studies Education Research, 9 (1), 106-123. Retrieved from http://dergipark.org.tr/jsser/issue/37945/438319

Jones, A. (2019). Parallel Oppressions. Journal of Culture and Values in Education, 2(1), 18-33. Retrieved from http://cultureandvalues.org/index.php/JCV/article/view/31

Karim, K. H. (2007). Nation and diaspora: Rethinking multiculturalism in a transnational context. International Journal of Media and Cultural Politics, 2(3), 267-282. https://doi.org/10.1386/macp.2.3.267_1

Karim, K. H. \& Eid, M. (2014). Imagining the other. In M. Eid \& K. H. Karim (Eds.), Re-imagining the other: Culture, media, and western-Muslim Intersections (pp. 1-23). New York, NY: Palgrave Macmillan.

Maddox, A. (2016). Research methods and global online communities: A case study. London, UK; New York, NY: Routledge. 
Mahmod, J. (2018). Online-Offline Research on Diasporic Identity: Methodological Benefits, Challenges and Critical Insights. In B. Baser, M. Toivanen, B. Zorlu, and Y. Duman (Eds.), Methodological Approaches in Kurdish Studies: Theoretical and Practical Insights from the Field (pp. 35-50). Lanham, MD: Rowman and Littlefield.

Mahmod, J. (2016). Kurdish diaspora online: From imagined community to managing communities. New York, NY: Palgrave Macmillan.

Maira, S. M. (2002). Desis in the house: Indian American youth culture in New York City. Philadelphia, PA: Temple University Press.

McDowall, D. 2004. A modern history of the Kurds. London, UK: I.B. Tauris.

Mishra, S. (2006). Diaspora criticism. Edinburgh, UK: Edinburgh University Press.

Modood, T. (2010). Multicultural citizenship and Muslim identity politics. Interventions: International Journal of Postcolonial Studies, 12(2), 157-170. https://doi.org/10.1080/1369801X.2010.489688

Ponzanesi, S., \& Leurs, K. (2014). On digital crossings in Europe. Crossings: Journal of Migration \& Culture 5(1), 3-22. https://doi.org/10.1386/cjmc.5.1.3_1

Pyke, K., \& Dang, T. (2003). 'FOB' and 'whitewashed': Identity and internalized racism among second generation Asian Americans. Qualitative Sociology, 26(2), 147-172. https://doi.org/10.1023/A:1022957011866

Said, E. (1978). Orientalism. London, UK: Penguin Books.

Schein, L. (2000). Minority rules: The Miao and the feminine in China's cultural politics. Durham, NC: Duke University Press.

Solas, E., \& Sutton, F. (2018). Incorporating Digital Technology in the General Education Classroom. Research in Social Sciences and Technology, 3(1), 1-15. Retrieved from http://ressat.org/index.php/ressat/article/view/338

Strunc, A. (2019). The Politics of Culture. Journal of Culture and Values in Education, 2(1), 71-80. Retrieved from http://cultureandvalues.org/index.php/JCV/article/view/26

Tajfel, H. (1981). Human groups and social categories. Cambridge, England: Cambridge University Press.

Tarman, B., \& Dev, S. (2018). Editorial: Learning Transformation through Innovation and Sustainability in Educational Practices. Research in Social Sciences and Technology,3(1), i-ii. Retrieved from http://ressat.org/index.php/ressat/article/view/363

Thangaraj, S. (2014). 'We're 80\% more patriotic': Atlanta's Muslim Community and the performances of cultural citizenship. In S. Jackson (Ed.), Routledge publication's handbook on race, class, and gender (pp. 220230). Abingdon, UK: Routledge.

Thangaraj, S. (2015). Desi hoop dreams: Pick-up basketball and the making of Asian American masculinity. New York, NY: New York University Press. https://doi.org/10.1017/S002187581700175X

Ugurlu, O. (2014). Identity Formation and Community Organization among Kurdish Diaspora in London. Journal of Ethnic and Cultural Studies, 1(1), 22-34.

Vertovec, S. (2000). Religion and diaspora. Institute of Social \& Cultural Anthropology. University of Oxford.

Wise, J.M. (2000). Home: territory and identity. Cultural Studies, 14(2), 295-310. https://doi.org/10.1080/095023800334896

Woofter, S. (2019). [Book Review]: Building Equity: Policies and Practices to Empower All Learners. American Journal of Qualitative Research, 3(1), 136-139. https://doi.org/10.29333/ajqr/5815

Yuval-Davis, N. (1993). Women, ethnicity, empowerment. International Institute of Social Studies of Erasmus University (ISS), 151, 1-20. https://doi.org/10.1177/0959353594041010 